\title{
Stiffness and Vibration Characteristics of SMA/ER3 Composites with Shape Memory Alloy Short Fibers
}

Qing-Qing Ni ${ }^{\text {a }}$, Run-xin Zhang ${ }^{\mathrm{b}}$, Toshiaki Natsuki ${ }^{\mathrm{c}}$, Masaharu Iwamoto ${ }^{\mathrm{b}}$

${ }^{a}$ Dept. of Functional Machinery and Mechanics,

Shinshu University,

3-15-1 Tokida, Ueda 386-8567, Japan

${ }^{\mathrm{b}}$ Division of Advanced Fibro-Science,

Kyoto Institute of Technology

Matsugasaki sakyo-ku, Kyoto 606-8585, Japan

${ }^{c}$ Faculty of Engineering, Shinshu University,

Wakasato 4-17-1, Nagano-shi, 380-8553, Japan

* Corresponding author

Prof. Qing-Qing Ni

E-mail: niqq@shinshu-u.ac.jp

Fax: +81-268-215438

Tel: $+81-268-215438$ 


\section{ABSTRACT}

Shape memory alloys (SMAs) possess both sensing and actuating functions due to their shape memory effect, pseudo-elasticity, high damping capability and other remarkable characteristics. Combining the unique properties of SMAs with other materials can create intelligent or smart composites. In this paper, epoxy resin composites filled with NiTi alloy short fibers were developed. Microstructure was observed using digital HF microscope. The dynamic mechanical properties were investigated by measuring the first vibration mode of clamped cantilever beams and by dynamic mechanical analysis (DMA). Moreover, the natural frequency of SMA composites was predicted theoretically. As a result, the temperature dependency of vibration property and DMA characteristics is affected largely due to an addition of SMA short fibers. The vibrational characteristics of SMA composites can be improved by the addition of small amounts of SMA short fibers. The addition of $3.5 \mathrm{wt} \%$ of SMA short fiber content to epoxy resin resulted in the maximum increment in both natural frequency and storage modulus. This suggested there exists an optimum SMA fiber content for vibration characteristics.

Key words: Shape memory alloy, short fiber, Composite, Shape-memory characteristics, Mechanical property 


\section{Introduction}

Smart materials respond to environmental stimuli in particular condition have attracted growing interest because of the sensor and actuator functions leading to many potential applications [1-2]. In particular, shape memory alloys (SMA) is used as a major element for smart composites due to their unique properties such as shape memory effect, pseudo-elasticity, and high damping capacity. The recent researches have extensively focused on the SMA composites because they have significant potential applications for vibrational and structural controls [3-6]. However, most of these researches were still limited to the shapes such as fibers, ribbons and films [7-9]. There are some faults in using these shapes. For example, (1) the process for fabrication of SMA composites is complicated; (2) although there is an advantage in controlling initial strain of structural materials in terms of the actuator function of SMAs, the huge recovery stress of SMAs results in the pull out of SMA fibers from matrix; (3) for the ribbon or thin-film SMAs, the interfacial failure between the SMAs and matrix occurs easily because the fabrication process generates higher residual stress.

On the other hand, though the shape memory effect and the actuator function is weakened by distributing SMA fibers or particles to the matrix, discontinuous SMAs have an advantage of dispersing the residual stress in matrix. Therefore, discontinuous SMA composites are expected to contribute improvement in fiber pull out and interfacial failure. Moreover, the discontinuous SMA composites can be easily fabricated by hand-layup method at low-cost.

Few researches on composite materials with SMA particles and fibers have been investigated up to now [10]. Wang et al. [11-12] have reported an approach to model SMA composites with discontinuous fibers, and examined the phase dependency of internal stress as a function of fiber aspect and fiber content. However, there is no systemic investigation on the effect of vibration characteristic in discontinuous SMA composites with short fibers.

In the present paper, SMA composites with NiTi discontinuous fibers were fabricated. The 
main objective is to develop advanced composites with high damping properties in terms of the phase transformation temperature of SMAs. Considering effective use of SMA's function, we designed the laminated composites with two layers, epoxy bulk layer and a composite layer with SMA short fibers and epoxy resin. Then the static mechanical property of two-layer laminated composites was evaluated using three-point bending test and dynamic mechanical test. The dynamic mechanical property was investigated by measuring the first vibration mode of clamped cantilever beams. Also, the comparison between theoretical calculation and experimental results are carried out based on the composite-beam theory and Halpin-Tsai equations.

\section{Experimental Procedures}

\subsection{Materials}

The SMAs in the present study were Ti-Ni alloy (KIOKALLOY-R) produced by Daido Steel Co., Ltd., Japan. The diameter and length of SMAs are about $0.2 \mathrm{~mm}$ and $1.5-2 \mathrm{~mm}$, respectively. The polymer used as a matrix was ER3 epoxy resin, and the hardening agent was EH208W produced by GHCRFT Co., Ltd., Japan. The ER3 epoxy resin had a high impact resistance property, and the glass transition temperature $\left(T_{g}\right)$ was approximately $140^{\circ} \mathrm{C}$. The engineering constants of Ti-Ni alloy and ER3 epoxy resin were listed in Table 1.

\subsection{Specimen fabrication}

After SMA fibers were well dispersed into ER3 epoxy resin, air bubbles in the epoxy resin solution were removed by a vacuum pump for 20 minutes and then the epoxy resin was poured into a mold and cured at room temperature for 24 hours. Finally, the molding was moved to a heating oven and heated from $40{ }^{\circ} \mathrm{C}$ to $140{ }^{\circ} \mathrm{C}$ at a rate of $10{ }^{\circ} \mathrm{C} / \mathrm{hr}$. Two-layer composites of the epoxy bulk layer and SMA fiber reinforced layer were molded by controlling the dispersion 
of SMA short fibers for different fiber content. The weight content of SMA fibers are designed by $0 \%, 3.5 \%, 5.1 \%, 16.1 \%$ and $27.4 \%$, respectively, which were represented by $0 \mathrm{wt} \%$, $3.5 \mathrm{wt} \%$, and so on.

\subsection{Experimental tests}

\subsubsection{Image of microscope}

The dispersions of SMA short fibers were observed using digital HF microscope (KEYENCE, VH-8000).

\subsubsection{Measurement of phase transformation in SMA fiber}

In order to investigate the effects of thermal history on the SMAs, the phase transformation temperature of SMAs was measured using Differential Scanning Calorimetry, Press Release Co., Ltd. The measured sample of SMAs was $2 \mathrm{mg}$ weight with a diameter of $0.2 \mathrm{~mm}$. The measurements were performed in nitrogen flow optimization. The temperature circle is from $-20^{\circ} \mathrm{C}$ to $100^{\circ} \mathrm{C}$ under heating and cooling rates of $10^{\circ} \mathrm{C} / \mathrm{min}$.

\subsubsection{Three-point bending test}

The samples $40 \times 5 \times 1.2 \mathrm{~mm}^{3}$ were cut out, and three-point bending tests were performed using Instron Universal Testing Instrument (Type 4466). The cross-head speed was $1 \mathrm{~mm} / \mathrm{min}$ under static loading, and the span length was $30 \mathrm{~mm}$. AD converter and computer were used to obtain the load-deflection curves. The specimen geometry for three-point bending tests was shown in Fig. 1.

\subsubsection{Measurement o vibration properties}

The samples $125 \times 12 \times 1.2 \mathrm{~mm}^{3}$ were cut out. The samples were first heated up to $130^{\circ} \mathrm{C}$ using a heating furnace, following 10 minutes for holding. The specimens, clamped in the form of cantilever beams with $100 \mathrm{~mm}$ span, were vibrated by initial deformation at the end with 20 mm. An acceleration sensor (PV-94 Rion), AD converter and computer were used to measure 
the natural frequency of the beams when the specimens were freely cooled down. The surface temperature on the specimens was measured with thermo tracer TH3100 (NEC mishiei Co., Ltd.). Figure 2 shows the schematic illustration of experimental setup for vibration testing. In terms of Fourier transformation, the vibration characteristics were obtained from damping waveforms measured.

\subsection{DMA measurement}

The samples $40 \times 5 \times 1.2 \mathrm{~mm}$ were cut out and dynamic mechanical experiments (DMA) were carried out. Experimental data of DMA tests were collected at synthesis frequencies of 10, $20,40,80$, and $160 \mathrm{~Hz}$, and at temperature from 0 to $250^{\circ} \mathrm{C}$ at the rate of $2{ }^{\circ} \mathrm{C} / \mathrm{min}$.

\section{Theoretical approaches}

\subsection{Flexural rigidity}

Figure 3 shows a model for two-layer laminated composite with a epoxy bulk layer and SMA/ER3 composite layer. The solution of the flexural rigidity properties can be obtained in terms of composite-beam and Halpin-Tsai models. According to composite-beam theory, the flexural rigidity EI in a two-layer laminated composite beam as shown in Fig. 3 could be given by

$$
E I=E_{c} I_{c}+E_{m} I_{m}
$$

where $I, I_{c}, I_{m}$ are the moment of inertia of the cross section in the two-layer laminated composite beam, SMA/ER3 composite layer and epoxy bulk layer, respectively. We have

$$
\begin{aligned}
& I_{C}=\frac{b}{3}\left[\left(t_{C}-e\right)^{3}+e^{3}\right] \\
& I_{m}=\frac{b}{3}\left[\left(t_{C}+t_{m}-e\right)^{3}-\left(t_{C}-e\right)^{3}\right] \\
& I=\frac{b}{3}\left[\left(t_{C}+t_{m}-e\right)^{3}+e^{3}\right]
\end{aligned}
$$

and the mid-plane position $e$ is obtained from

$$
e=\frac{E_{c} t_{c}^{2}+E_{m} t_{m}\left(2 t_{c}+t_{m}\right)}{2\left(E_{c} t_{c}+E_{m} t_{m}\right)}
$$


where $t_{c}$ and $t_{m}$ are the thickness of the SMA/ER3 composite layer and epoxy bulk layer, and $E_{c}$ and $E_{m}$ are the modulus of the SMA/ER3 composite layer and epoxy bulk layer, respectively. $b$ is width.

For the SMA/ER3 composite layer with randomly oriented discontinuous SMA short fibers in two dimensions, the modulus $\left(E_{c}\right)$ is given by [13]

$$
E_{c}=\frac{3}{8} E_{L}+\frac{5}{8} E_{T}
$$

Based on the Halpin-Tsai equations, the modulus along the longitudinal and transverse directions can be represented by

$$
\begin{aligned}
& E_{L}=\frac{E_{m}\left(1+2 \xi \eta_{L} V_{f}\right)}{1-\eta_{L} V_{f}}, \quad \xi=L / D \\
& E_{T}=\frac{E_{m}\left(1+2 \eta_{T} V_{f}\right)}{1-\eta_{T} V_{f}}
\end{aligned}
$$

and

$$
\eta_{L}=\frac{E_{f} / E_{m}-1}{E_{f} / E_{m}+2 \xi}, \quad \eta_{T}=\frac{E_{f} / E_{m}-1}{E_{f} / E_{m}+2}
$$

where $E_{f}$ and $E_{m}$ are the modulus of the SMAs and the epoxy, respectively. The data of the storage modulus for both ER3 epoxy bulk and SMA fibers are shown in Table 2 [14]. $V_{f}$ is the volume fraction of the fibers. $L$ and $D$ are the fiber length and diameter, respectively.

From Eq. (1), the flexural modulus $E$ in a two-layer laminated composite beam is given by

$$
E=\left(E_{c} I_{c}+E_{m} I_{m}\right) / I
$$

\subsection{Natural vibrational frequency}

For a simple elastic beam problem with uniform cross-sectional area, a well-known natural frequency can be given by [15]

$$
f=\frac{\beta^{2}}{2 \pi l^{2}} \sqrt{\frac{E I}{S \rho}}
$$

where $S$ and $l$ are the cross-section area and the length of the composite beam, respectively. $\beta$ 
is a constant relative to vibration bound condition. In a cantilever beam, $\beta$ is equal to 1.875 for the first mode of vibration. $\rho$ is the density of composite beam. $E I$ is the equivalent bending stiffness obtained from Eq. (1).

In order to predict the natural frequencies of the composites as a function of temperature, the material constants of ER3 epoxy resin for different temperatures were obtained according to dynamic mechanical analysis (DMA) and the elastic modulus for the ER3 and the SMA as shown in Table 2 are used.

\section{Results and Discussion}

\subsection{Microstructural observation}

The physical and mechanical properties of SMA/ER3 composites will largely depend on dispersion of SMA fillers into matrix. Figure 4 shows the surface observation of the SMA/ER3 composite layer using digital HF microscope. The images shown in Figs. 4 (a) and (b) are the surfaces of the SMA/ER3 composite layers with $3.5 \mathrm{wt} \%$ and $16.1 \mathrm{wt} \%$ of SMA short fibers, respectively. Black and blank parts in the images represent SMA fillers and epoxy resin, respectively. The uniform distributions of SMA fibers were observed from these images although small aggregations exist occasionally in some regions.

\subsection{Phase transformation of SMAs}

The shape memory alloys undergo diffusionless martensitic transformations on cooling beyond critical temperatures, $\mathrm{M}_{\mathrm{s}}$, which are dependent upon alloy composition, processing procedures and thermal/mechanical treatment condition. Figure 5 shows the differential scanning calorimetry (DSC) curves demonstrating the hysteresis of the phase transformation in used SMAs. The phase transition of SMAs occurs when the temperature increases. The

beginning $\left(A_{s}\right)$ and end $\left(A_{f}\right)$ temperatures of the austenite transformation are from about 
$60^{\circ} \mathrm{C}$ to $70^{\circ} \mathrm{C}$. In the cooling process, R-phase transformation is involved at the temperature of approximate $60^{\circ} \mathrm{C}$ to $42^{\circ} \mathrm{C}$. The martensite phase transformation temperature occurs from about $21^{\circ} \mathrm{C}$ to $2^{\circ} \mathrm{C}$.

\subsection{Flexural properties}

Figure 6 shows Young's modulus and fracture deflection in the developed two-layer laminated composites with different SMA weight contents. The equivalent elasticity modulus in bending tests increased with the increment of SMA fiber weight content, while the fracture deflections decreased. These results suggest that the SMA short fiber composites show brittle fracture behavior for high SMA fiber content. Figure 7 shows comparison of predicted and experimental results on elastic modulus for developed two-layer laminated composite beam. The theory calculation of stiffness properties agrees reasonably with the experiment values.

\subsection{Vibrational properties}

\subsubsection{Temperature of natural frequency}

Figure 8 shows the variation of natural frequency in SMA composites with temperature for different SMA contents. The natural frequencies of composites with embedded SMAs are larger than that of ER3 epoxy bulk at any temperature. An addition of a small amount of SMA fibers results in larger increment of natural frequency compared with resin bulk. However, it is found that $3.5 \mathrm{wt} \%$ of SMA fibers indicated a maximum natural frequency. After this amount, the natural frequency of the SMA composites decreases with increasing SMA contents. For the SMA composites with $5.1 \mathrm{wt} \%$ and $3.5 \mathrm{wt} \%$, the natural frequency of vibration rises between $45^{\circ} \mathrm{C}$ and $60^{\circ} \mathrm{C}$. Especially, a peak value of the natural frequency around $60^{\circ} \mathrm{C}$ is obviously observed for the SMA content of $3.5 \mathrm{wt} \%$. This is due to the increment of stiffness for more than three times in SMA fibers when the phase transformation from martensite to austenite structures occurs (see 
Fig. 5).

To clarify the influence of SMA fibers on the vibrational properties, the data in Fig. 8 normalized by the epoxy resin specimen are shown in Fig. 9. It is obvious that the effect of the filled SMA fibers on the natural frequency of the SMA composites is significant. For the composites with SMA fiber contents of $3.5 \mathrm{wt} \%, 5.1 \mathrm{wt} \%, 16.1 \mathrm{wt} \%$, and $27.4 \mathrm{wt} \%$, the natural frequencies respectively increased by 1.26 times, 1.21 times, 1.10 times, and 1.08 times at a temperature $60^{\circ} \mathrm{C}$ compared to the epoxy resin beam. This indicated that the design of damping controls by using SMAs should be possible.

\subsubsection{Damping behavior}

A beneficial use of the SMAs is their good damping property at super-elastic status. Several damping parameters, such as inner friction, loss factor and loss tangent $(\tan \delta)$ have been used individually or combined for metals, ceramics, and rubbers, according to the material properties and test methods. For the present composites with SMA fibers, the logarithm attenuation coefficient is used, which can be evaluated by measuring the vibration amplitude during the experiment. A classical damping equation for vibration beams is given by

$$
\Delta=\ln \left(x_{n} / x_{n+1}\right)
$$

where $x_{n}, x_{n+1}$ are the amplitude of sine wave with logarithm damping in different intervals.

Figure 10 shows the relation between temperature and logarithmic attenuation coefficient. The logarithmic attenuation coefficient increases with the increment of SMA fiber content, but decreases with increasing temperature. The results suggest that it is possible to improve temperature dependency of the damping properties of composites by making use of SMA short fibers.

According to Eqs. (1) and (11), temperature dependency of natural frequency in SMA composites could be predicted theoretically (Fig. 11). Compared with the experimental results 
as shown in Fig. 8, the predicted values exhibit lager natural frequencies. However, it is seen that the temperature history of natural frequencies has an agreement between the theoretical and experimental results.

\subsubsection{Characteristics of dynamic mechanical analysis (DMA)}

The effects of SMA short fiber contents on the storage modulus are investigated as shown in Fig. 12. It is found that the storage moduli of SMA composites are affected largely by SMA short fiber content. In the ER3 epoxy bulk, the storage modulus almost linearly decreased with the temperature. However, an addition of SMA fibers into the ER3 epoxy results in considerable increment of storage modulus in SMA composites, particularly at the temperatures over $80^{\circ} \mathrm{C}$ due to the austenite transformation of TiNi alloys. An peak of storage modulus between $80{ }^{\circ} \mathrm{C}$ to $120^{\circ} \mathrm{C}$ is observed. This is mainly because the stiffness of SMA fiber becomes large after the phase transformation from martensite to austenite and it contributes to the storage modulus in SMA composites. Seeing the values of storage modulus at $120^{\circ} \mathrm{C}$, when SMA fiber contents is less than $3.5 \mathrm{wt} \%$ the storage modulus increases with increasing fiber weight content, but it decreases for SMA fiber content larger than $3.5 \mathrm{wt} \%$. This may suggest that an optimal content of SMA fillers exists in the SMA fiber composites. To clarify the effect of SMA fibers on storage moduli, the data in Fig. 13 were normalized by ER3 epoxy bulk. It is obvious that the effect of SMA fibers on storage modulus is significant especially over the phase transformation temperature. For example, at the temperature of $120^{\circ} \mathrm{C}$, the SMA composite with $3.5 \mathrm{wt} \%$ of SMA fiber content is of the storage modulus as large as six times in ER3 epoxy bulk.

Figure 14 shows the change of storage modulus between the start and finish temperatures of austenite phase transformation as a function of SMA fiber contents. It is found that the amount of $3.5 \mathrm{wt} \%$ is a key point for the change in storage modulus from increment to decrement during phase transformation. This may be considered due to the effects of thermal stress 
between SMA fiber and matrix [16]. At high temperature region over a certain limit, the residual thermal stress around fibers decreases with increasing fiber contents. This implies that the interfacial strength between SMA fibers and matrix becomes small. Therefore, the stiffness ratio (SMA vs. ER3) in SMA/ER3 composite layer decreases with the increment of fiber contents $[17,18]$. The temperature history in SMA fibers and between SMA fiber and epoxy matrix in SMA/ER3 composites may be confirmed by the change of storage modulus between minimum storage modulus at about $80^{\circ} \mathrm{C}$ and the maximum at about $120^{\circ} \mathrm{C}$.

The loss factors of the SMA fiber composites are shown in Fig. 15. The loss factor tan $\delta$ has a maximum peak when the SMA composites are heated through the glass transition region of epoxy resin around $140^{\circ} \mathrm{C}$. The peaks shift to a slightly lower temperature when SMA fiber contents increase and this indicates that the glass transition temperature of the SMA composites becomes low by the addition of SMA fibers. The peak values in $\tan \delta$ curves increase with the increment of SMA fiber contents.

\section{Conclusions}

The shape memory alloy based composites with SMA short fibers are developed as a sample of free design of SMAs for composite structure. In order to enforce the active function of SMAs application, the two-layer laminated composites are designed and the temperature dependency of vibrational characteristics are investigated. The results suggest that the vibrational characteristics of SMA composites can be improved by the addition of small amounts of SMA short fibers. The addition of 3.5wt $\%$ of SMA short fiber content to epoxy resin resulted in the maximum increment in both natural frequency and storage modulus as large as 1.26 times and 6 times of epoxy bulk, respectively. Moreover, the attenuation coefficient of the developed SMA composites increases with increasing SMA short fiber contents. The theoretical analysis of natural frequency is performed in terms of the present 
model, and the predicted results agree reasonably with the experimental ones.

Acknowledgements--This project is partly supported by the fund of 21 st Century COE Program (Japanese government) - Advanced fiber science and textile technology in Shinshu university.

\section{References}

[1] Wei ZG, Tang CY, Lee WB. Design and fabrication of intelligent composites based on shape momory alloys. Journal of Materials Processing Technology 1997;69:68-74.

[2] Ma N, Song G. Control of Memory Alloy Actuator Using Pulse Width (PW) Modulation. Smart Structures and Materials 2002: Modeling, Signal Processing, and Control, Vittal S. Rao, Editor, Proceedings of SPIE 2002;4693:348-359.

[3] Piedboeuf MC, Gauvin R, Thomas M. Damping behaviour of shape memory alloys: strain amplitude, frequency and temperature effects. Journal of Sound and Vibration 1998;214:5:855-901.

[4] Kin-tak lau. Vibration characteristics of SMA composite beams with different boundary conditions. Materials and Design 2002;23:741-749.

[5] Ostachowicz WM, Kaczmarczyk S. Vibrations of composite plates with SMA fibers in a gas stream with defects of the type of delamination. Composite Structures 2001;54:305-311.

[6] Park JS, Kim JH, Moon SH. Vibration of thermally post-buckled composites embedded with shape momory alloy fibers. Composite Structures 2004;63:179-188.

[7] Sato M, Sekine H, Hayakawa Y. Vibration Characteristics and Optimization of Symmetric CFRP Laminates Containing Embbedded Shape Mwmory Alloy Fibers. Transactions of the Japan Society of Mechanical Engineers A 2002;68:668:30-38. 
[8] Aoki Y. Characteristics of Vibration Suppression for SMA/CF and SMA/GF Hybrid Composites. Aoki Y, Department Precision Machinery Enginnering, College of Sciences and Technology, Nihon Uniwersity, 7-24-1 Narashino-dai, Funabashi, Chiba, 274-8501 Japan.

[9] Duana B, Tawfika M, Goekb SN, Roa JJ, Meia C. Vibration of laminated composite plates embedded with shape memory alloy at elevated temperatures. Department of Aerospace Engineering, Old Dominion Univ., Norfolk, VA 23529, ES de Mecanique de Marseille, Marseille, France.

[10] Murasawa G, Tohgo K and Ishii H. Deformation Behavior and Fracture Process of NiTi/Polycarbonate Shape Memory Alloy Composites under Thermo-Mechanical Loading. Transactions of the Japan Society of Mechanical Engineers A 2000;66:650:1901-1907.

[11] Wang J, Sze KY and Shen YP. Studying the thermomechanical behavior of SM composites with aligned SMA short fibers by micromechanical approaches. Smart Materials and Structures 2001;10:990-999.

[12] Wang J and Shen YP. Micromechanics of composites renforced in the aligned SMA short fibers in uniform thermal fields. Smare Materials and Structures 2000;9:69-77.

[13] Biagiotti J, Fiori S, Torre L. Mechanical Properties of polypropylene matrix composites reinforced with natural fibers: A statistical approach. Polymer Composites 2004;25:26-36.

[14] Zhang RX, Ni QQ, Matusda A, Yamamura T, Iwamoto M. Vibration Characteristics of Laminated Composite Plates with Embedded Shape Memory Alloys. Composite structures 2005 , in press.

[15] Dym CL, Shames IH. Solid mechanics: A vibrational approach. New York: McGraw-Hill; 1973.

[16] Nazhat SN, Joseph R, Wang M, Smith R, Tanner KE, Bonfield W. Dynamic mechanical 
characterization of hydroxyapatite reinforced polyethylene: effect of particle size. Journal of Materials Science: Materials in Medicine 2000;11:625.

[17] Todd RI, Boccaccini AR. Theamal residual stresses and their toughening effect in $\mathrm{AL}_{2} \mathrm{O}_{3}$ platelet reinforced glass. Acta mater. 1999;47:11:3236.

[18] Aoki TN, Inoue T. High performance polymer alloy. MARUZAN Pub. Co.; $1994 ; 140-152$. 
Figure captions

Fig. 1 Specimen for bending test

Fig. 2 Schematic illustration of equipment of vibration experiment

Fig. 3 Calculation model of two-layer laminated composite with SMA short fibers

Fig. 4 Surface image of specimens (a) with $3.5 \mathrm{wt} \%$, and (b) $16.1 \mathrm{wt} \%$ of SMA fibers

Fig. 5 Phase transformation of SMA wire $(\Phi 0.2 \mathrm{~mm})$

Fig. 6 Young's modulus and fracture deflection for different SMA weight contents

Fig. 7 Influence of SMA fiber contents on flexural elastic modulus

Fig. 8 Variation of natural frequency with temperature for different SMA fiber contents

Fig. 9 Temperature dependency of normalized natural frequency by ER3 epoxy bulk specimen

Fig. 10 Temperature dependency of damping coefficient for different SMA fiber contents

Fig. 11 Theoretical prediction of temperature dependency of natural frequency.

Fig. 12 Storage modulus-temperature curves in SMA composites with different SMA fiber contents

Fig. 13 Normalized storage modulus-temperature curves in SMA composites with different SMA fiber contents.

Fig. 14 Variation of storage modulus at the temperatures of $80^{\circ} \mathrm{C}$ and $120^{\circ} \mathrm{C}$

Fig. 15 Loss factor $\tan \delta$ as a function of temperature for different SMA fiber contents

Table 1 Material constants.

Table 2 Storage modulus of ER3 epoxy resin and SMA fiber. 
Figure 1

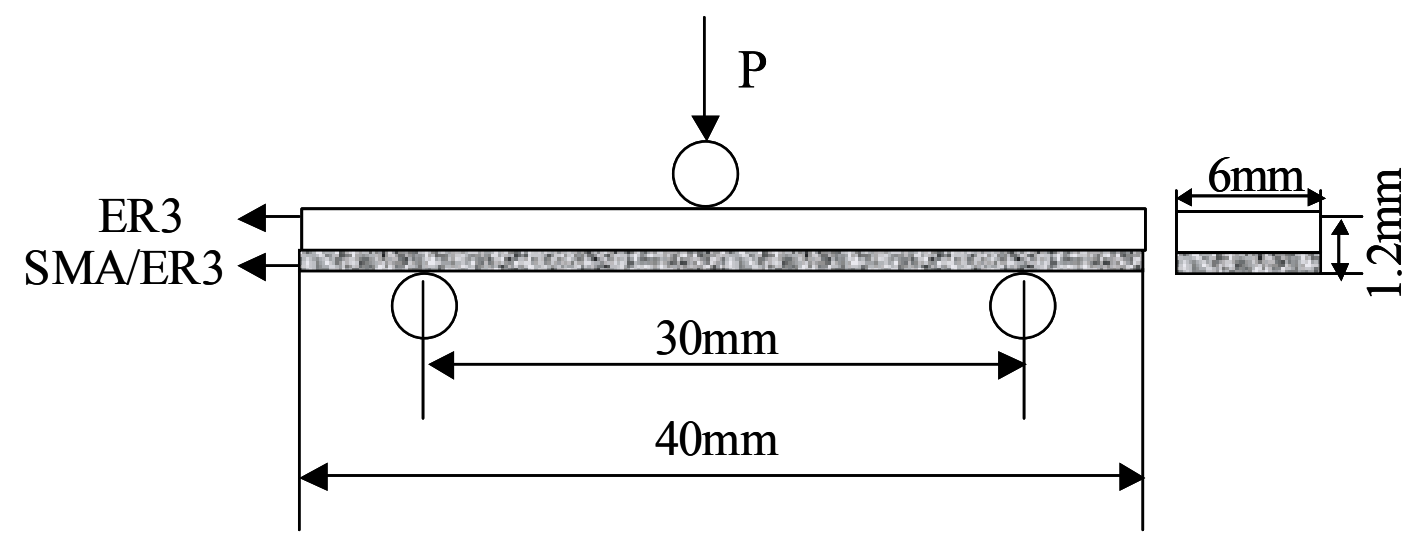

Figure 2

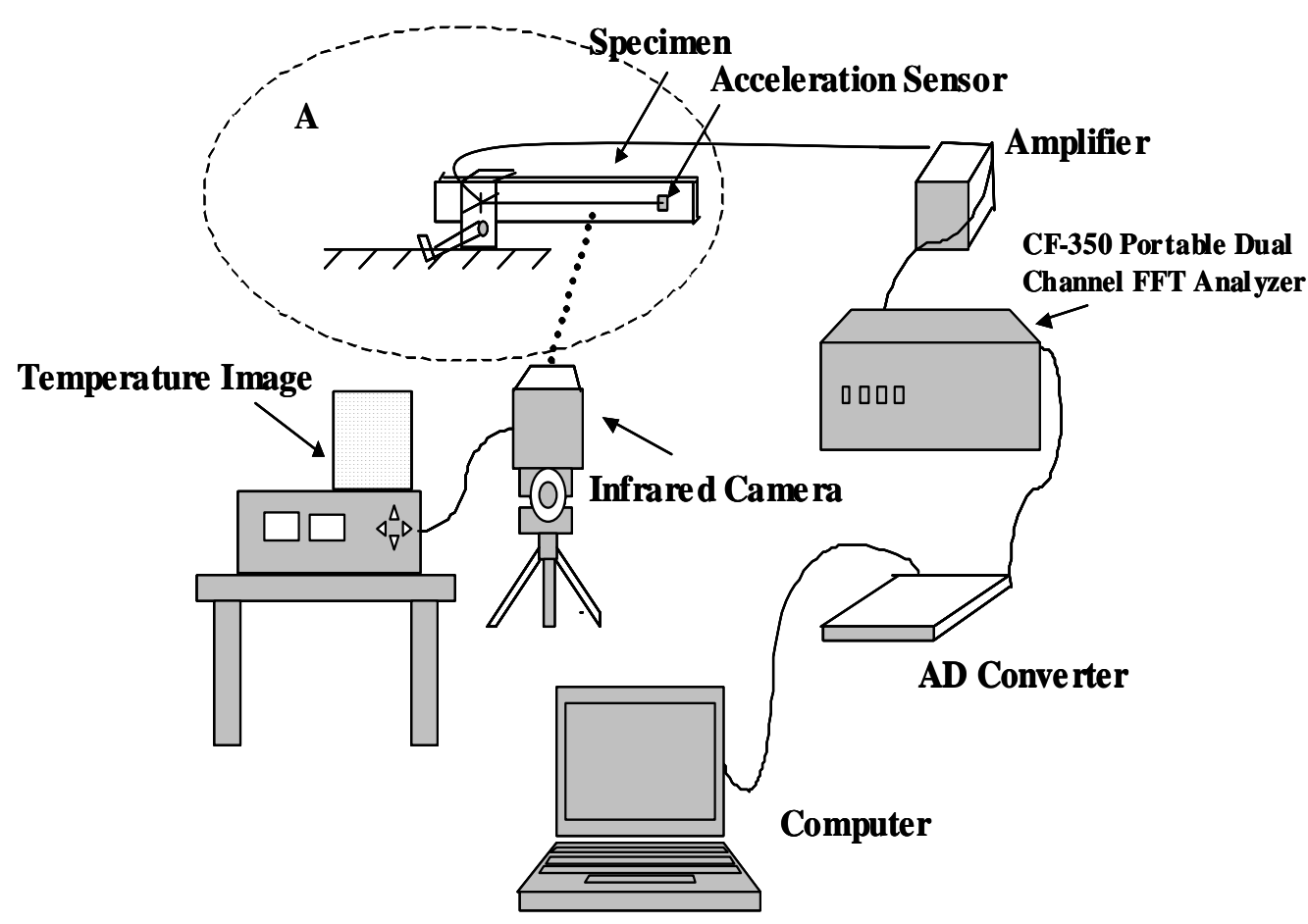


Figure 3

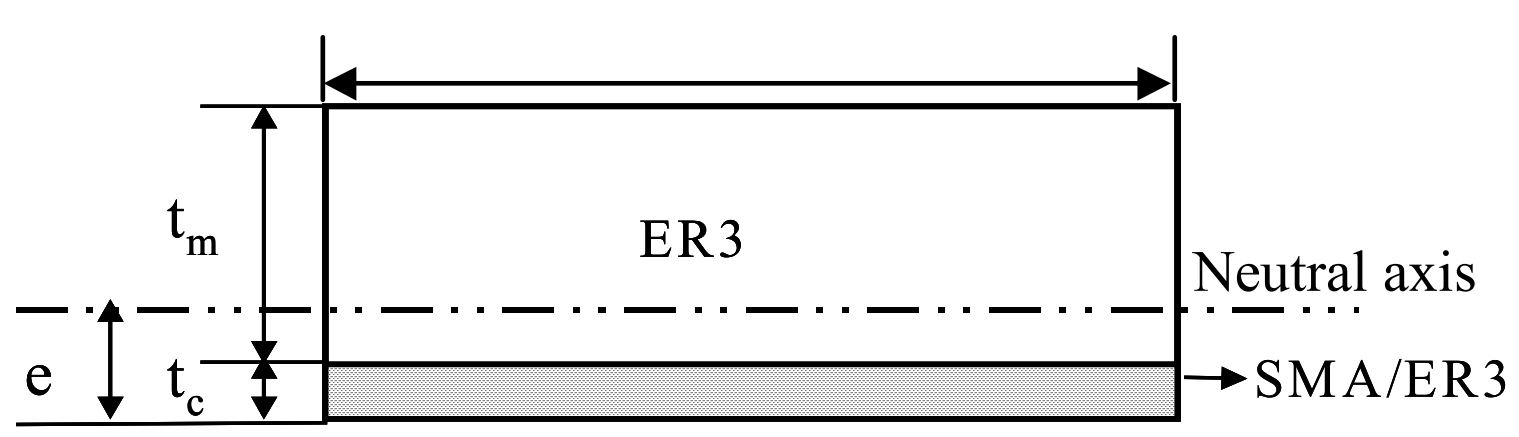

Figure 4

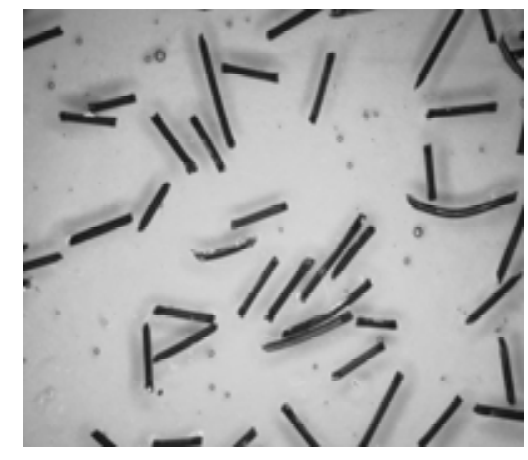

$1 \mathrm{~mm}$

(a) $3.5 \mathrm{wt} \%$ (short fiber)

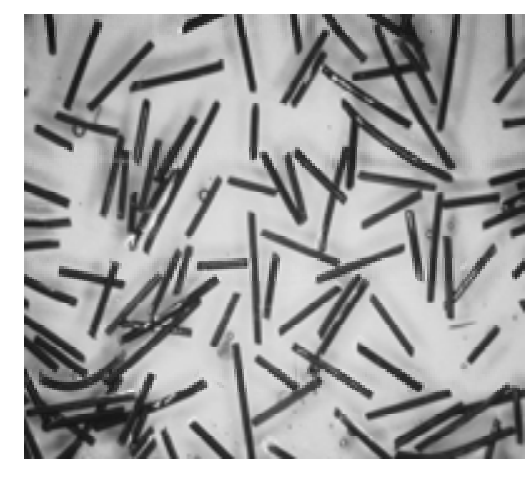

$1 \mathrm{~mm}$

(b) $16.1 \mathrm{wt} \%$ (short fiber) 
Figure 5

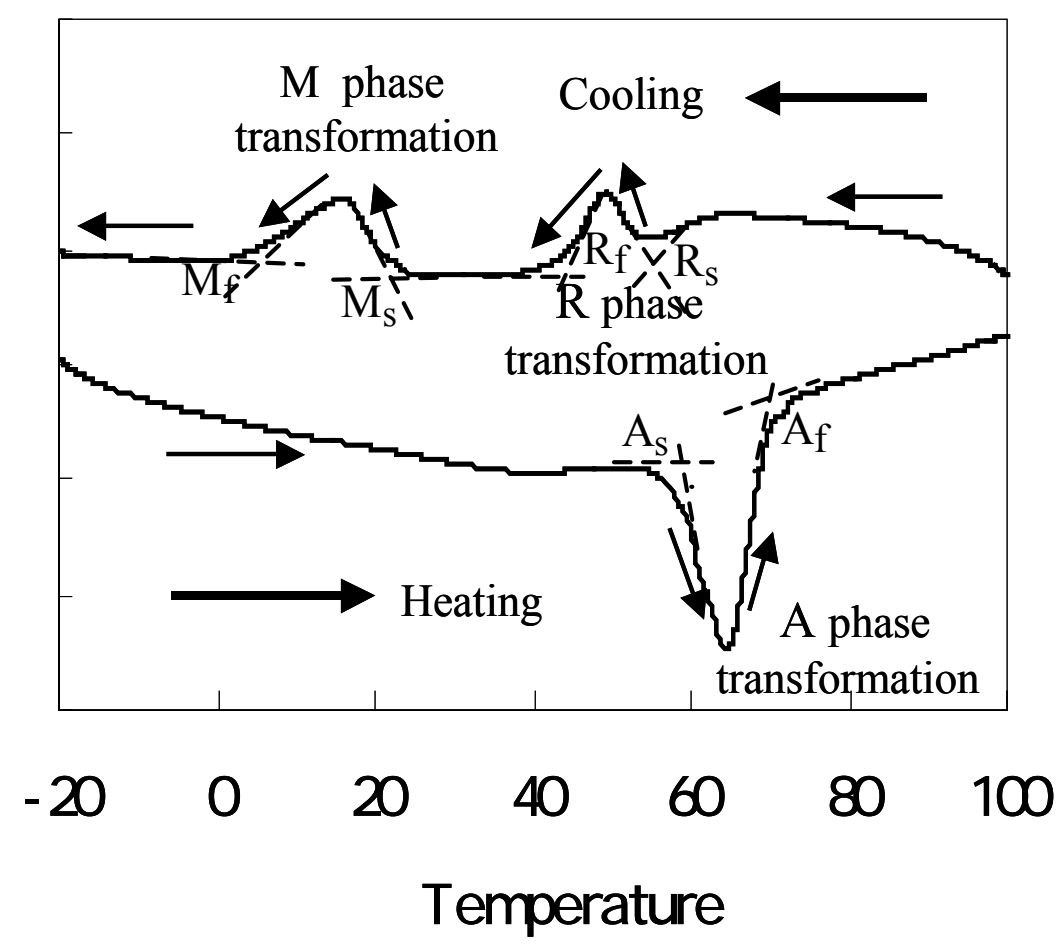

Figure 6

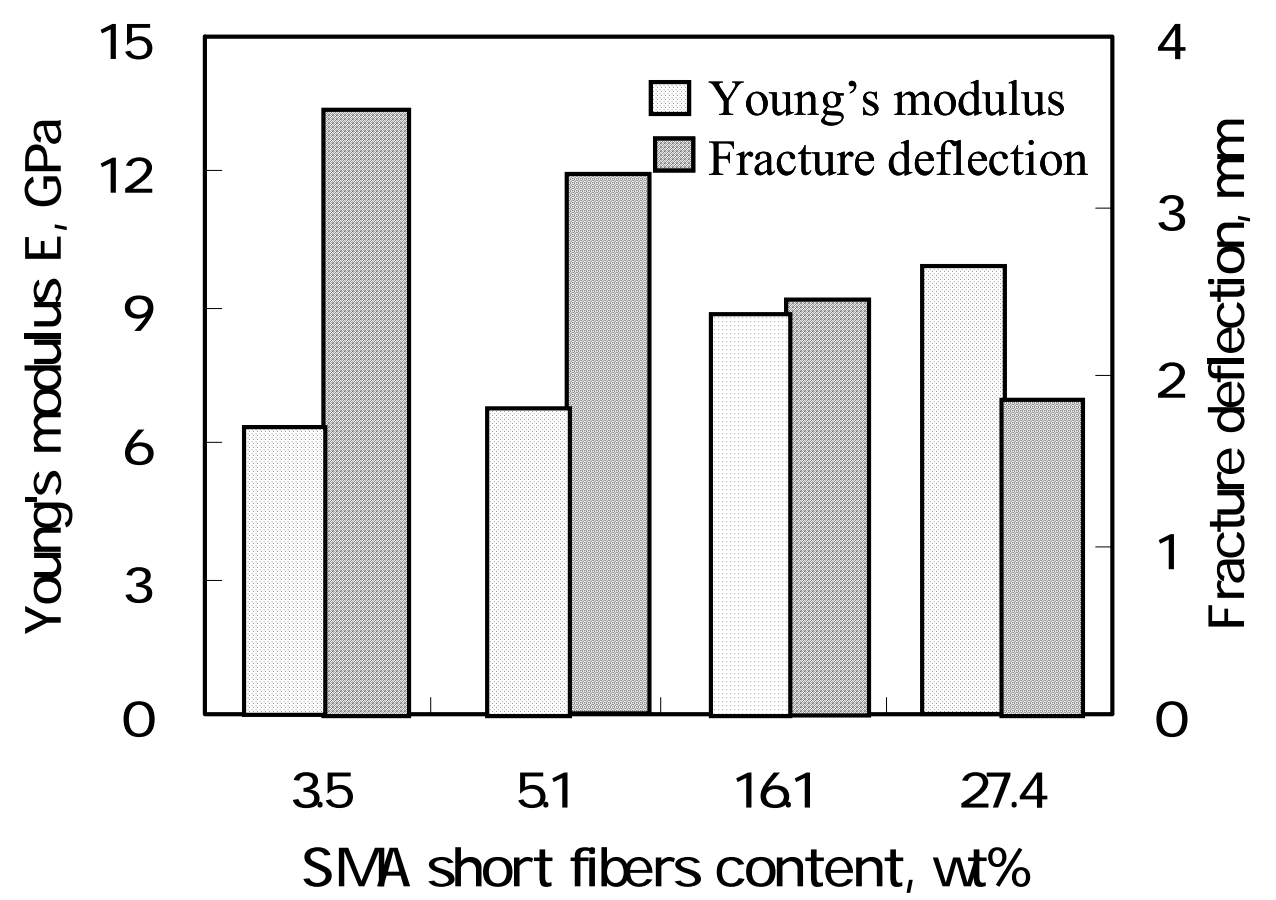


Figure 7

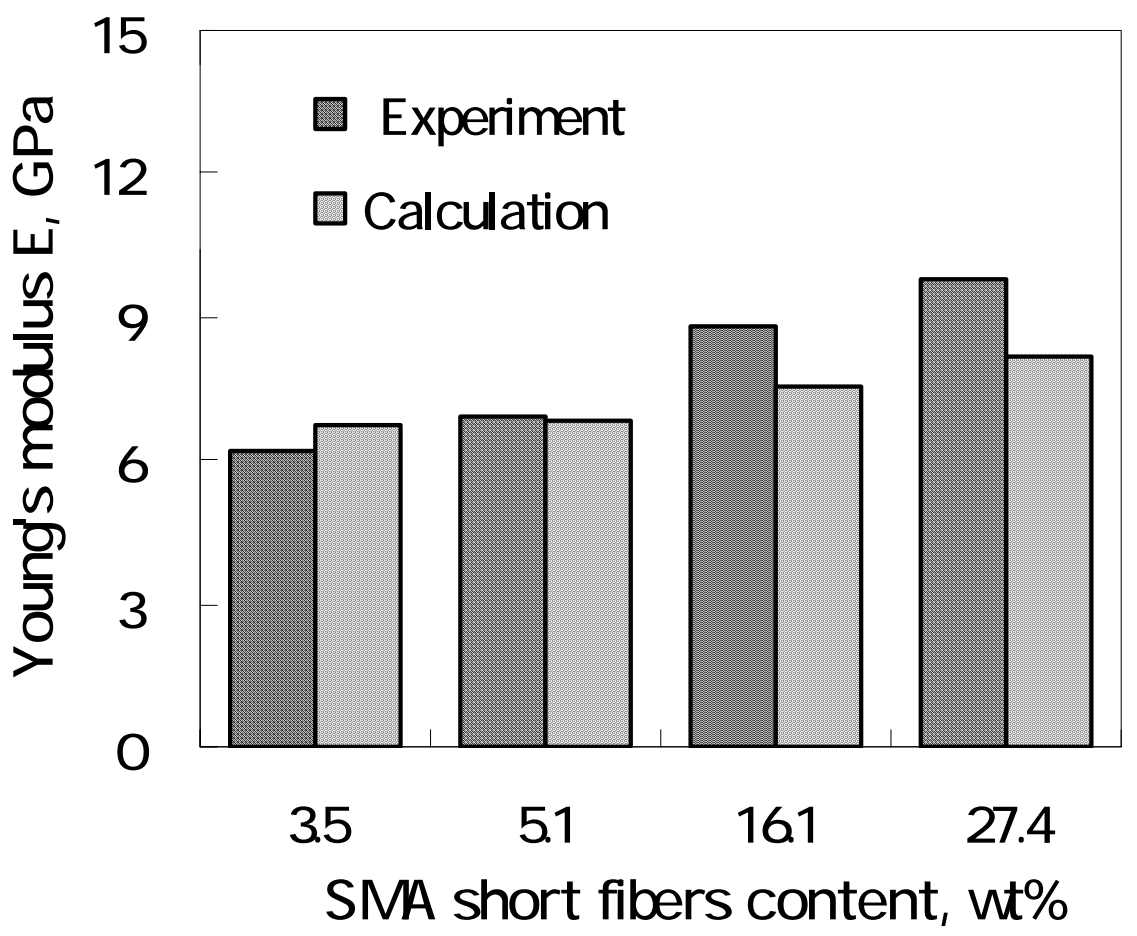

Figure 8

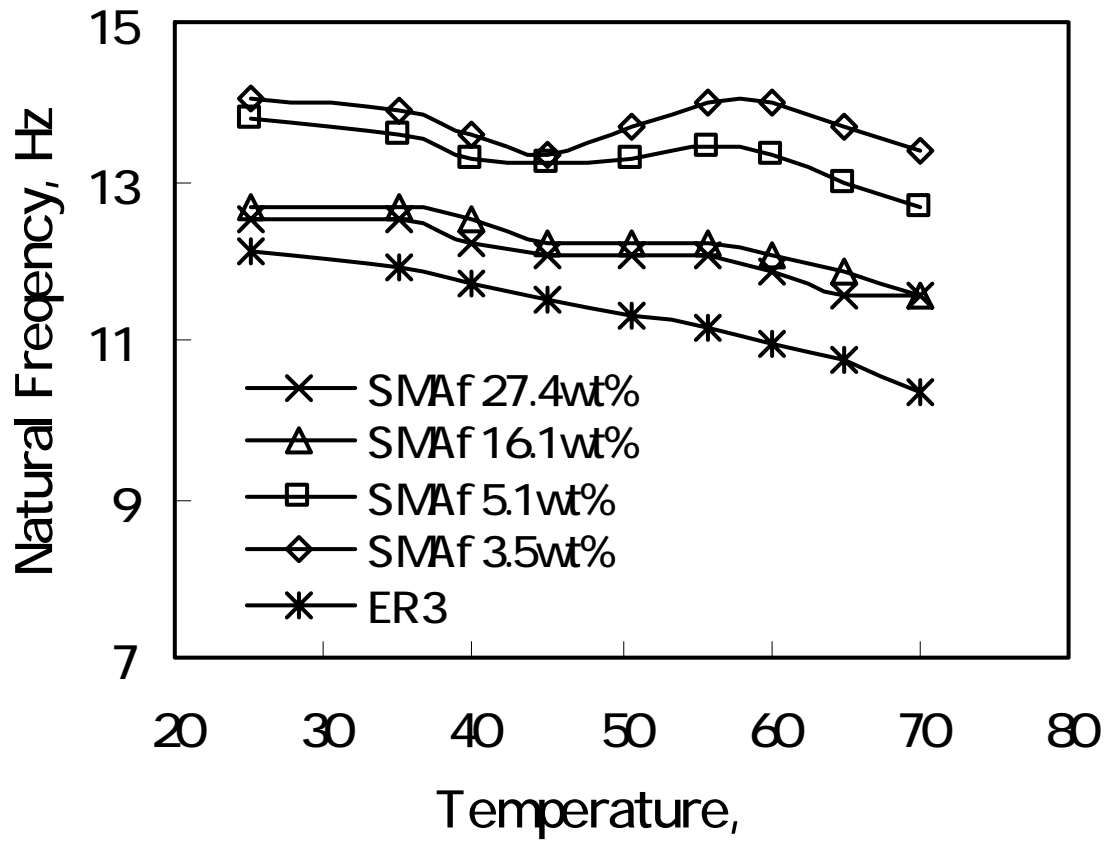


Figure 9

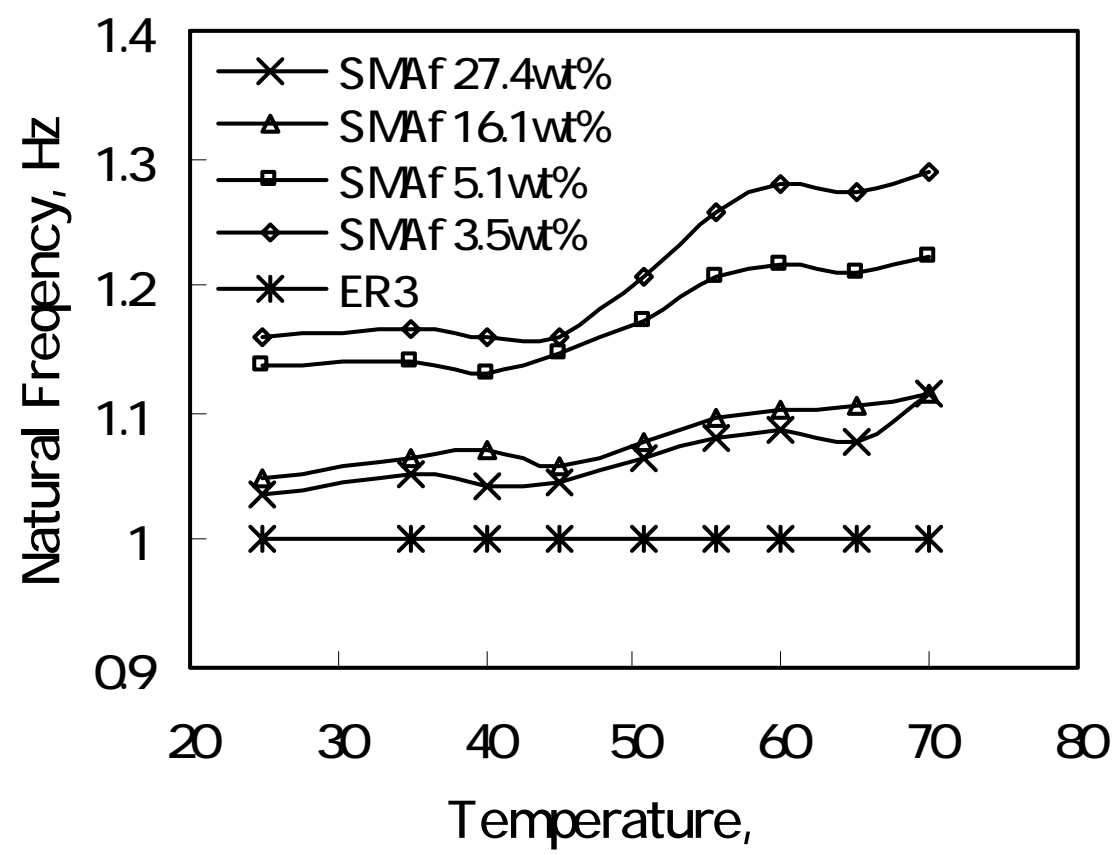

Figure 10

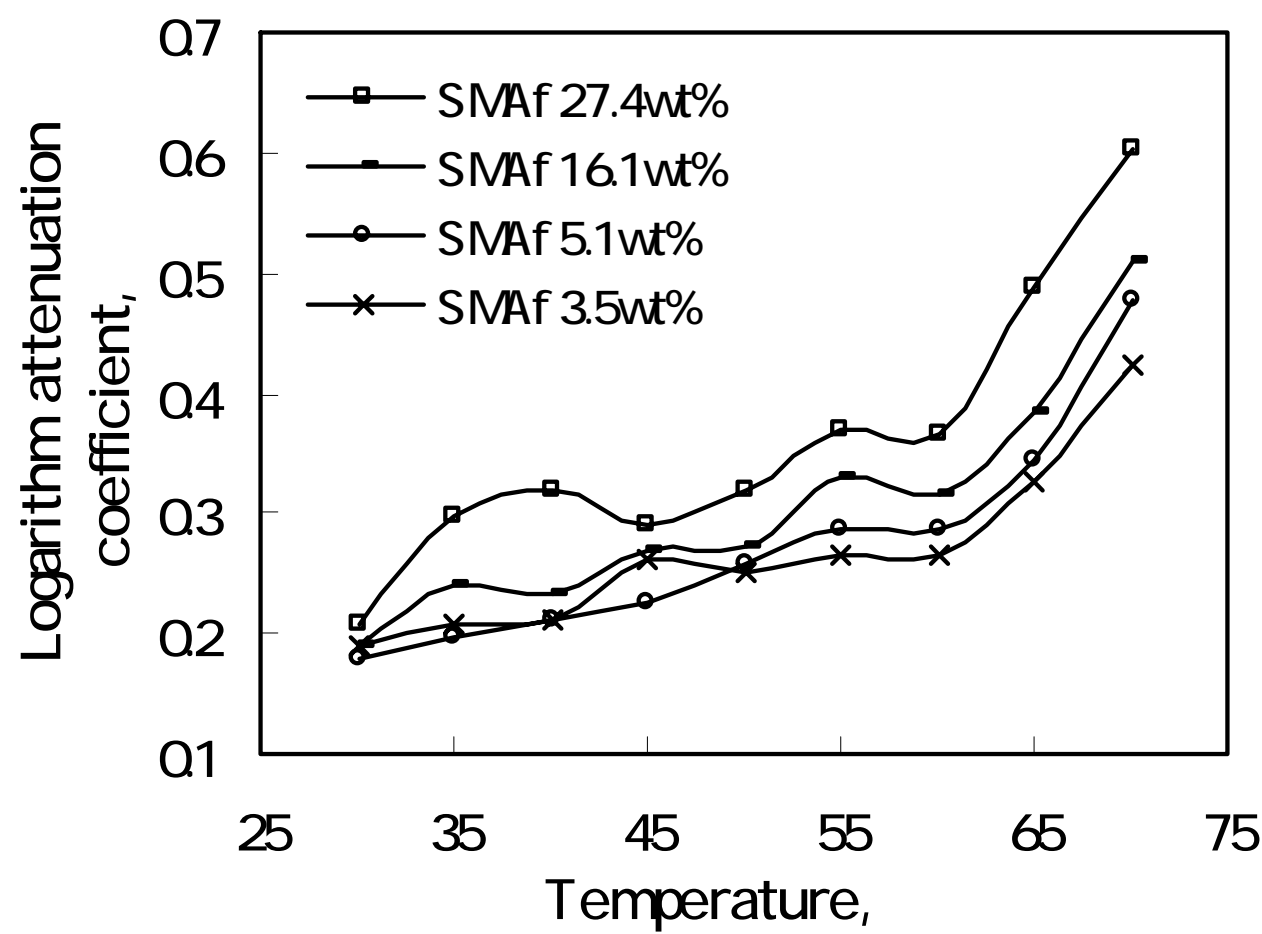


Figure 11

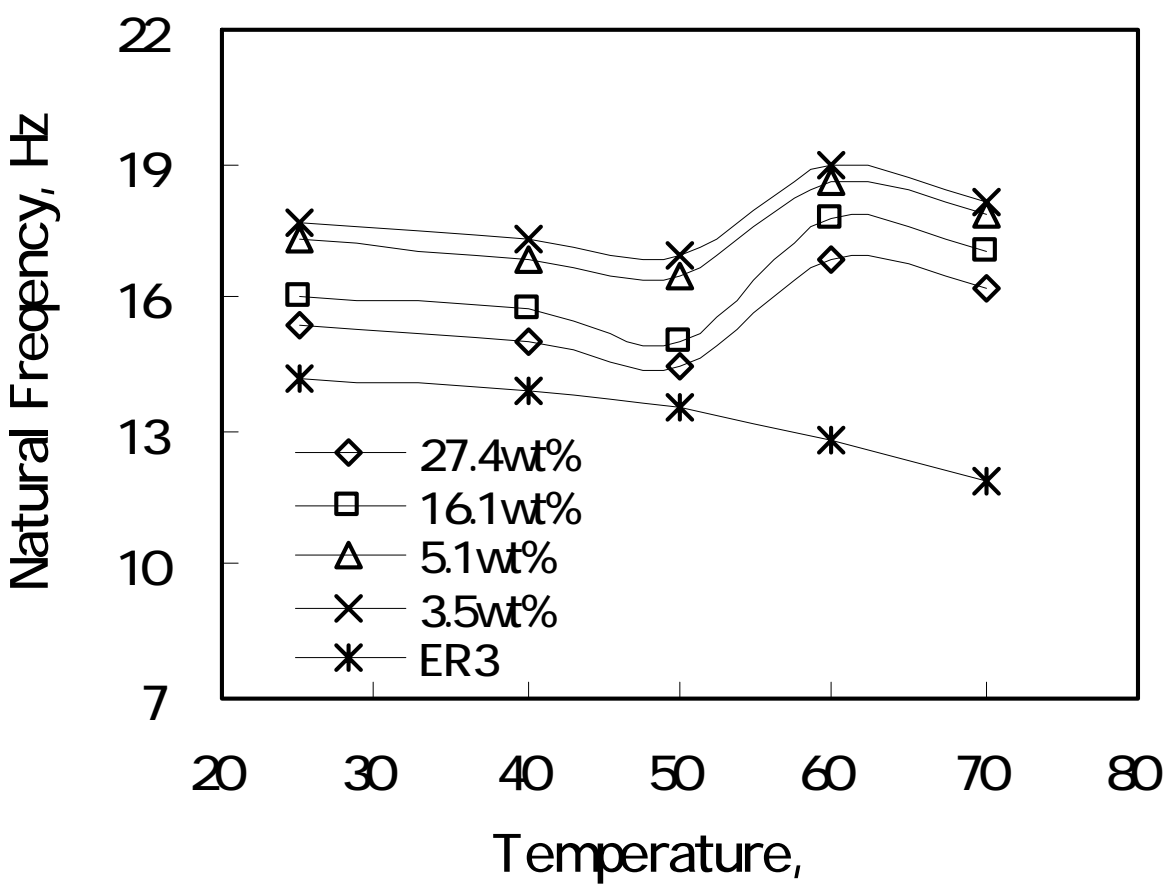

Figure 12

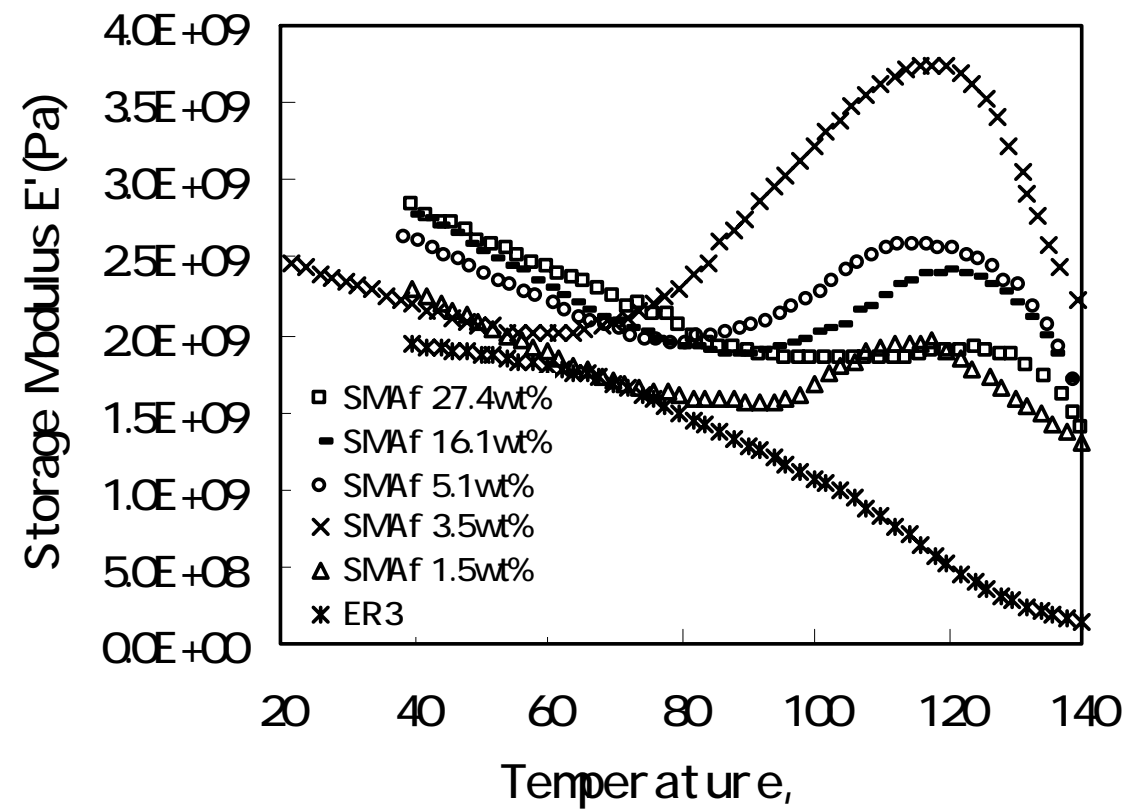


Figure 13

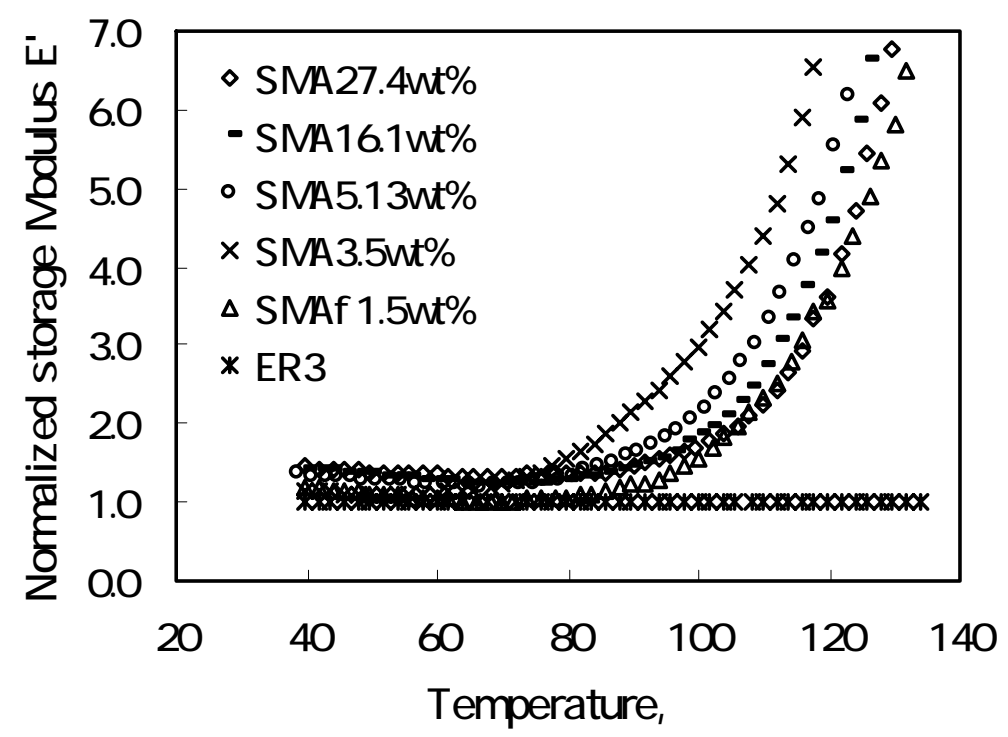

Figure 14

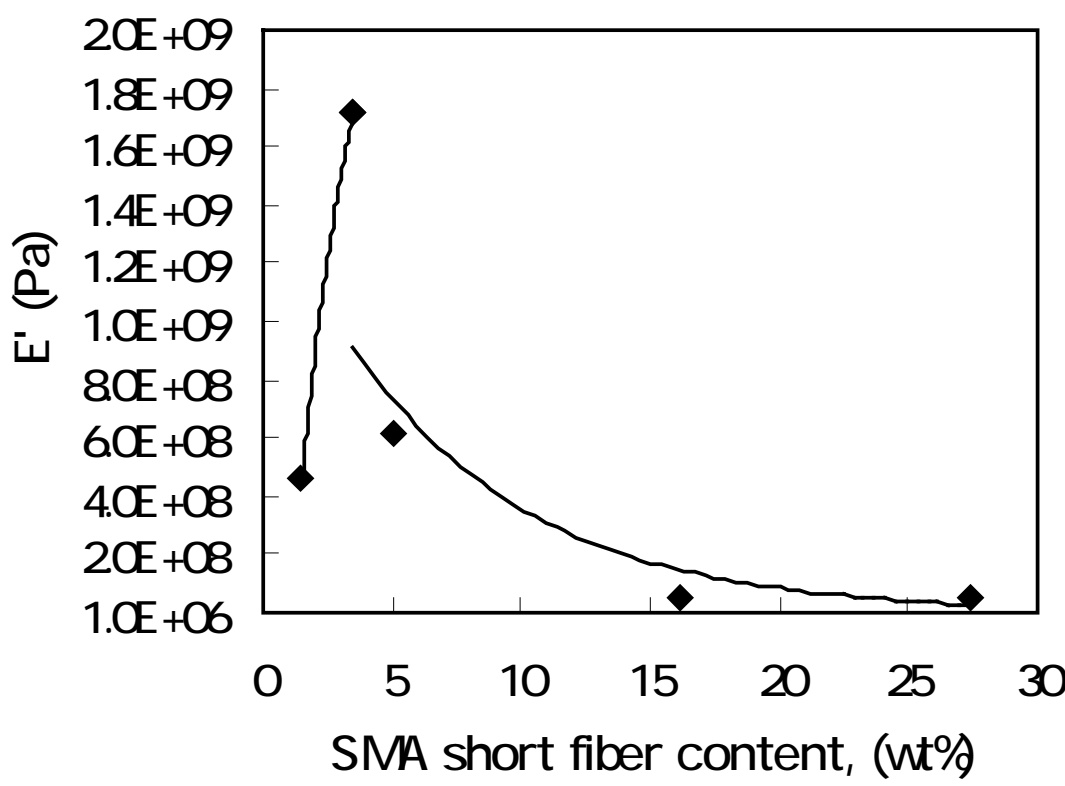


Figure 15

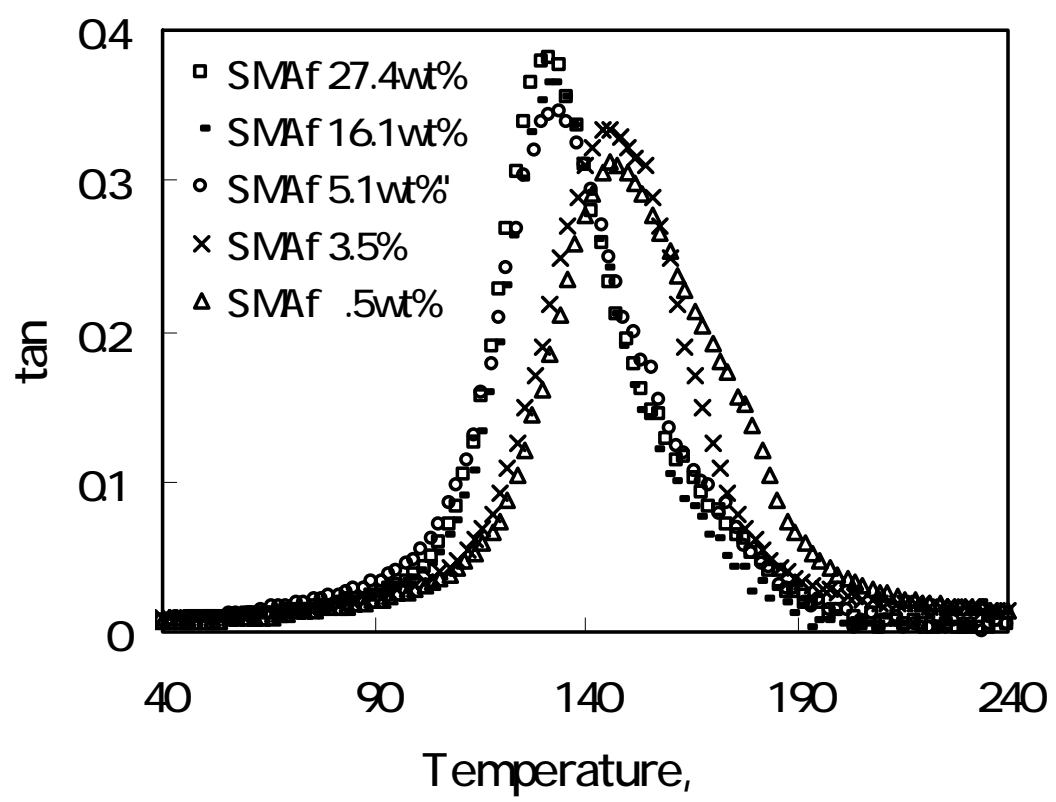

Table 1

\begin{tabular}{c|c|c|c|c}
\hline Materials & $\begin{array}{c}\text { Elastic } \\
\text { modulus } \\
(\mathrm{GPa})\end{array}$ & $\begin{array}{c}\text { Density } \\
\left(\mathrm{kg} / \mathrm{m}^{3}\right)\end{array}$ & $\begin{array}{c}\text { SMA } \\
\text { length }(\mathrm{mm})\end{array}$ & $\begin{array}{c}\text { Glass Temperature } \\
\left({ }^{\circ} \mathrm{C}\right)\end{array}$ \\
\hline \hline SMA & $\begin{array}{c}20.4\left(\mathrm{~T}<\mathrm{A}_{\mathrm{s}}\right) \\
71.4\left(\mathrm{~T}>\mathrm{A}_{\mathrm{f}}\right)\end{array}$ & 6500 & $1 \sim 2$ & - \\
\hline ER3 & 6.5 & 1150 & - & 140 \\
\hline
\end{tabular}

Table 2

\begin{tabular}{c|c|c}
\hline Temperature, ${ }^{\circ} \mathrm{C}$ & $\begin{array}{c}\mathrm{ER3} \\
\mathrm{E}^{\prime}, \mathrm{GPa}\end{array}$ & $\begin{array}{c}\mathrm{SMA}(\Phi 0.2 \mathrm{~mm}) \\
\mathrm{E}^{\prime}, \mathrm{GPa}\end{array}$ \\
\hline \hline 30 & 2.07 & 20.4 \\
40 & 1.99 & 20.4 \\
50 & 1.95 & 20.4 \\
60 & 1.85 & 71.4 \\
70 & 1.71 & 71.4 \\
\hline
\end{tabular}

